2001s-03

\title{
Testing and Comparing Value-at-Risk Measures
}

Peter Christoffersen, Jinyong Hahn, Atsushi Inoue

\begin{tabular}{c}
\hline Série Scientifique \\
Scientific Series
\end{tabular}

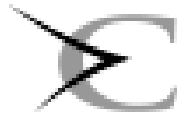

Montréal

Janvier 2001 


\section{CIRANO}

Le CIRANO est un organisme sans but lucratif constitué en vertu de la Loi des compagnies du Québec. Le financement de son infrastructure et de ses activités de recherche provient des cotisations de ses organisationsmembres, d'une subvention d'infrastructure du ministère de la Recherche, de la Science et de la Technologie, de même que des subventions et mandats obtenus par ses équipes de recherche.

CIRANO is a private non-profit organization incorporated under the Québec Companies Act. Its infrastructure and research activities are funded through fees paid by member organizations, an infrastructure grant from the Ministère de la Recherche, de la Science et de la Technologie, and grants and research mandates obtained by its research teams.

\section{Les organisations-partenaires / The Partner Organizations}

-École des Hautes Études Commerciales

-École Polytechnique

-Université Concordia

-Université de Montréal

-Université du Québec à Montréal

-Université Laval

-Université McGill

-MEQ

-MRST

-Alcan Aluminium Ltée

-AXA Canada

-Banque Nationale du Canada

-Banque Royale du Canada

-Bell Québec

-Bombardier

-Bourse de Montréal

-Développement des ressources humaines Canada (DRHC)

-Fédération des caisses populaires Desjardins de Montréal et de l'Ouest-du-Québec

-Hydro-Québec

-Imasco

-Industrie Canada

-Pratt \& Whitney Canada Inc.

-Raymond Chabot Grant Thornton

-Ville de Montréal

(C) 2001 Peter Christoffersen, Jinyong Hahn et Atsushi Inoue. Tous droits réservés. All rights reserved. Reproduction partielle permise avec citation du document source, incluant la notice ( $)$.

Short sections may be quoted without explicit permission, provided that full credit, including $\odot$ notice, is given to the source.

Ce document est publié dans l'intention de rendre accessibles les résultats préliminaires de la recherche effectuée au CIRANO, afin de susciter des échanges et des suggestions. Les idées et les opinions émises sont sous l'unique responsabilité des auteurs, et ne représentent pas nécessairement les positions du CIRANO ou de ses partenaires.

This paper presents preliminary research carried out at CIRANO and aims at encouraging discussion and comment. The observations and viewpoints expressed are the sole responsibility of the authors. They do not necessarily represent positions of CIRANO or its partners.

\section{ISSN 1198-8177}




\title{
Testing and Comparing Value-at-Risk Measures*
}

\author{
Peter Christoffersen ${ }^{\dagger}$, Jinyong Hahn ${ }^{\ddagger}$, Atsushi Inoue ${ }^{\S}$
}

\begin{abstract}
Résumé / Abstract
La valeur exposée au risque (value at risk - VaR) est devenue un outil standard de mesure et de communication des risques associés aux marchés financiers. Plus de quatre-vingts fournisseurs commerciaux proposent actuellement des systèmes de gestion d'entreprise ou de gestion des risques commerciaux fournissant des mesures de type VaR. C'est donc souvent aux gestionnaires des risques qu'incombe la tâche difficile d'opérer un choix parmi cette pléthore de modèles de risques. Cet article propose un cadre utile pour déterminer par quel moyen le gestionnaire des risques peut s'assurer que la mesure de $\mathrm{VaR}$ dont il dispose est bien définie, et, dans un deuxième temps, comparer deux mesures de VaR différentes et choisir la meilleure en s'appuyant sur des données statistiques utiles. Dans l'application, différentes mesures de VaR sont calculées à partir soit de mesures de volatilité historiques ou de mesures de volatilité implicites dans le prix des options; les VaR sont également vérifiées et comparées.

Value-at-Risk (VaR) has emerged as the standard tool for measuring and reporting financial market risk. Currently, more than eighty commercial vendors offer enterprise or trading risk management systems which report VaR-like measures. Risk managers are therefore often left with the daunting task of having to choose from this plethora of risk models. Accordingly, this paper develops a framework for asking, first, how a risk manager can test that the VaR measure at hand is properly specified. And second, given two different VaR measures, how can the risk manager compare the two and pick the best in a statistically meaningful way? In the application, competing VaR measures are calculated from either historical or option-price based volatility measures, and the VaRs are tested and compared.
\end{abstract}

Mots Clés : Gestion des risques, volatilité, tests non emboîtés, options, risque modèle

Keywords: Risk management, volatility, nonnested testing, options, model risk

JEL: G10, C22, C53

\footnotetext{
${ }^{*}$ Corresponding Author: Peter Christoffersen, CIRANO, 2020 University Street, $25^{\text {th }}$ floor, Montréal, Qc, Canada H3A 2A5 Tel.: (514) 398-2869 Fax: (514) 398-3876 email: christop@management.mcgill.ca We would like to thank Mike Chernov and Eric Ghysels for providing us with their data, and Yuichi Kitamura for sharing his Gauss code. We would also like to thank participants at the 1998 Triangle Econometrics Conference and the 1999 Econometric Society European Meetings for helpful comments. The usual disclaimer applies.
}

\footnotetext{
$\dagger$ McGill University and CIRANO

* Brown University

$\S$ North Carolina State University
} 


\section{Motivation}

Sparked by the stock market crash in 1987, the past decade has witnessed a surge in the effort financial market participants devote to risk management. In a recent survey of risk management software, Risk (1999) lists more than eighty commercial vendors offering enterprise or trading risk management information systems. This effort has been encouraged by regulatory authorities imposing risk-based capital adequacy requirements on financial institutions (see Dimson and Marsh, 1995, and Wagster, 1996). The recent turbulence in emerging markets, starting in Mexico in 1995, continuing in Asia in 1997, and spreading to Russia and Latin America in 1998 has further extended the interest in risk management to companies outside the traditional sphere of banking and insurance.

Two important developments, one in academia and one on Wall Street have facilitated the advancement in knowledge about risk management. First, the development of volatility models for measuring and forecasting volatility dynamics began in academics with Engle (1982). The hundreds of papers following Engle's original work - many of them finding applications to financial data have had important implications for modern risk management techniques. Second, the introduction of RiskMetrics by JP Morgan (1996) has enabled companies with just a minimum of computational power and technical ability to compute simple measures of market risk for a given portfolio of assets. RiskMetrics has also aroused the interest of academics as it offers a benchmark methodology upon which improvements can be made, and against which alternatives can be tested. Research in this tradition is reported in Jorion (1996), Duffie and Pan (1997), Dowd (1998), and the November 2000 special issue of this Journal.

An important contribution of the RiskMetrics methodology is the introduction of the Valueat-Risk (VaR) concept which collapses the entire distribution of the portfolio returns into a single number which investors have found useful and easily interpreted as a measure of market risk. The VaR is essentially a $p$-percent quantile of the conditional distribution of portfolio returns.

In RiskMetrics, the VaR measure has only a few unknown parameters, which are simply calibrated to values found to work quite well in common situations. However, several studies such as Danielsson and de Vries (1997), Christoffersen (1998), and Engle and Manganelli (1999) have found significant improvements possible when deviations from the relatively rigid RiskMetrics framework are explored. But, when one attempts to apply the results which have emerged from the GARCH and related literatures to risk management, several questions remain open. We ask, first, given a VaR measure, how can the risk manager test that the particular measure at hand is appropriately specified? And second, given two different VaR measures, say one using GARCH and one using implied volatility, how can the risk manager compare the two and pick the best in a statistically meaningful way?

Choosing an appropriate VaR measure is an important and difficult task, and risk managers have coined the term Model Risk to cover the hazards from working with potentially misspecified models. Beder (1995), for example, compares simulation-based and parametric models on fixed income and stock option portfolios and finds apparently economically large differences in the VaRs 
from different models applied to the same portfolio. Hendricks (1996) finds similar results analyzing foreign exchange portfolios. Even more strikingly, Marshall and Siegel (1997) find that commercial risk management software from different vendors all using the same RiskMetrics model report apparently very different VaR measures for identical portfolios. They refer to this phenomenon as Implementation Risk. Unfortunately none of the papers contain formal statistical tests of the differences between the models, and a key purpose of our work is exactly to equip the risk managers with the tools necessary to assess the statistical significance of the differences between different VaR measures.

We illustrate the usefulness of our approach in an application to daily returns on the S\&P500 index. We test and compare VaR measures based on GARCH-type volatilities estimated from historical returns with measures based on implied and estimated volatilities from options contracts written on the S\&P500 index. We use the volatility measures constructed by Chernov and Ghysels (2000).

The development of a specification testing methodology is complicated by the fact that the VaR concept introduces an important nondifferentiability which invalidates existing statistical testing procedures. In addition, when comparing two competing measures, it is essential to allow for them to be nonnested. We tackle these challenges by extending the results in Kitamura (1997) to allow for nondifferentiability.

The remainder of our paper is structured as follows: In Section 2, we establish some notation and develop a moment-based framework for VaR specification and comparison testing. In Section 3, we introduce the econometric methodology and show how it can be applied to testing VaR models. In Section 4, we apply our methodology to returns on the S\&P500 index, comparing traditional time series based VaR measures to VaRs based on implied volatilities from options prices. Section 5 concludes and gives directions for future research.

\section{Value-at-Risk with Conditional Moment Restrictions}

We set out by defining the notation necessary for establishing our testing framework.

\subsection{Defining Value-at-Risk}

Let the asset return process under consideration be denoted by

$$
y_{t}=\mu_{t}+\varepsilon_{t}
$$

where $\varepsilon_{t} \mid \Psi_{t-1} \sim\left(0, \sigma_{t}^{2}\right)$, and where $\Psi_{t-1}$ is the time $t-1$ information set. Then the Value-at-Risk measure with coverage probability, $p$, is defined as the conditional quantile, $F_{t \mid t-1}(p)$, where

$$
\operatorname{Pr}\left(y_{t} \leq F_{t \mid t-1}(p) \mid \Psi_{t-1}\right)=p .
$$

The conditionality of the VaR measure is key. Throughout this paper, we will assume that $y_{t}$ is appropriately demeaned so that $\mu_{t}=0$ and $y_{t}=\varepsilon_{t}$. But volatility will be allowed to be timevarying. 


\subsection{Specifying Volatility}

Risk managers have a plethora of volatility measures to choose from when calculating Value-at-Risk (VaR) measures. Time series models of volatility range from exponentially smoothed and simple autoregressive models, over single-shock GARCH models, to two-shock stochastic volatility models. Furthermore, the risk manager can use option based measures of volatility to measure risk. Let us therefore first give a brief overview of available volatility models.

The benchmark measure advocated in JP Morgan's (1996) RiskMetrics sets the conditional mean constant, and specifies the variance as an exponential filter

$$
\sigma_{t}^{2}=(1-\lambda) \varepsilon_{t-1}^{2}+\lambda \sigma_{t-1}^{2},
$$

where $\lambda$ is simply set to .94 for daily data. The innovations are assumed to be Gaussian, thus the VaR measure is

$$
F_{t \mid t-1}^{R M}(p)=\mu+\Phi^{-1}(p) \sigma_{t}
$$

Obviously, for $p=.05$, we would have $\Phi^{-1}(p)=-1.64$. In the standard Gaussian GARCH $(1,1)$ case (Bollerslev 1986) the conditional variance evolves as

$$
\sigma_{t}^{2}=\omega+\alpha \varepsilon_{t-1}^{2}+\beta \sigma_{t-1}^{2},
$$

and the one-step ahead conditional quantile with coverage $p$ is

$$
F_{t \mid t-1}^{G}(p)=\mu_{t \mid t-1}+\Phi^{-1}(p) \sigma_{t}
$$

Stochastic Volatility models instead assume volatility is driven by an unobserved factor. In the simplest case,

$$
y_{t}-\mu_{t \mid t-1}=\varepsilon_{t} \exp \left(\frac{\sigma_{t}}{2}\right)
$$

where

$$
\sigma_{t}=\gamma_{0}+\gamma_{1} \sigma_{t-1}+\eta_{t-1}
$$

Within each type of volatility model, many variants exist, based on considerations regarding long versus short memory, nonlinear versus linear specifications, and exogenous variables such as seasonal and trading volume effects.

GARCH, RiskMetrics and stochastic volatility models are all based solely on the history of the return $y_{t}$ itself. But information on volatility may also be obtained from current market data such as option prices. In an effort to incorporate the market's belief about future returns, the risk manager can apply implied volatilities from options prices. Given data options contracts traded, the Black and Scholes (1972) implied volatility of a European call option can be found as the $\sigma$ which solves

$$
C=S \cdot \Phi\left(d_{1}\right)-\exp (-r(T-t)) K \cdot \Phi\left(d_{2}\right)
$$


where $C$ is the quoted options price, $\Phi(\cdot)$ is the standard normal c.d.f., and

$$
d_{1}=\frac{\log \frac{S}{K}+\left(r+\frac{\sigma^{2}}{2}\right)(T-t)}{\sigma \sqrt{T-t}}, \quad d_{2}=d_{1}-\sigma \sqrt{T-t} .
$$

where $K, S, r, T-t$, and $\sigma$ denote the strike price, the underlying asset price, the risk-free interest rate, the time-to-maturity, and the implied volatility respectively. Jorion (1995), for example, has found implied volatilities to work well as predictors of future volatility when using a standard mean squared error criterion.

One can also use option prices and asset returns to estimate a more realistic model of returns allowing for time-varying volatility. A benchmark model in this tradition is found in Heston (1993), who assumes that the price of the underlying asset, $S(t)$, evolves according to

$$
d S(t)=\mu S d t+\sqrt{v(t)} S d z_{1}(t)
$$

and volatility, $v(t)$, evolves according to

$$
d v(t)=\kappa[\theta-v(t)] d t+\sigma \sqrt{v(t)} d z_{2}(t)
$$

where the two Wiener process innovations, $d z_{1}(t)$ and $d z_{2}(t)$ are allowed to be correlated. Heston (1993) derives a closed-form solution for a European call option price which is similar in structure to equation (3). Chernov and Ghysels (2000) show how the parameters can be estimated using data on options and returns.

Other measures of volatility, which differ in the return data applied, include Garman and Klass (1980), and Gallant and Tauchen (1998) who incorporate daily high and low quotes, and Andersen and Bollerslev (1998) and Andersen, Bollerslev, Diebold and Labys (1999), who average intraday squared returns to estimate daily volatility.

In the empirical application at the end of the paper we will study VaR measures based on volatility measures from equations (1), (2), (3), and (4) respectively.

\subsection{Conditional Moment Restrictions}

Implicit in the context of risk management and the related pursuit of a good measure of volatility is an assumption that the return standardized by its conditional mean and some transformation of volatility, say $\xi\left(\sigma_{t}\right)$, is i.i.d.: If $\left(y_{t}-\mu_{t}\right) / \xi\left(\sigma_{t}\right)$ is not i.i.d. for any transformation $\xi(\cdot)$ of volatility, then volatility alone would not be sufficient for characterization of conditional quantile. Typically, we make an implicit assumption that $y_{t}$ belongs to a location-scale family: We assume that $\left(y_{t}-\mu_{t}\right) / \sigma_{t}$ is i.i.d., which would imply that the conditional quantile is some linear function of volatility, where the relevant coefficients of such a linear function is determined by the common distribution of the standardized return. Therefore, one can think of the VaR measure as the outcome of a quantile regression. Treating volatility as a regressor, and ignoring conditional mean dynamics, we have for example, that

$$
F_{t \mid t-1}\left(\beta_{p}\right)=\beta_{p, 1}+\beta_{p, 2} \sigma_{t}
$$


for some $\beta_{p, 1}$ and $\beta_{p, 2}$. Notice that the parameters will vary with the chosen coverage, $p$. A different VaR measure, based on a different volatility model $\sigma_{t}^{*}$, or a different distributional assumption, or both, could be written as

$$
F_{t \mid t-1}^{*}\left(\theta_{p}\right)=\theta_{p, 1}+\theta_{p, 2} \sigma_{t}^{*}
$$

Two questions now arise: First, "How do we evaluate the appropriateness of the specification of these measures?" And second, "How do we compare them?"

In order to answer these questions, we apply the following conditional moment framework: Consider first the specification testing question. Given the risk manager's information set, $\Psi_{t-1}$, and under the null that the VaR measure is correctly specified, the following must hold:

Definition 1 The VaR is efficient with respect to the information set, $\Psi_{t-1}$, when

$$
E\left[I\left(y_{t}<F_{t \mid t-1}\left(\beta_{p}\right)\right)-p \mid \Psi_{t-1}\right]=0
$$

where $I(\cdot)$ is the indicator function.

This moment condition states that no information available to the risk manager at time $t-1$ should help predict whether time $t$ 's return falls above or below the VaR measure reported at time $t-1$. The VaR measure should in other words be efficient with respect to the information set $\Psi_{t-1}$. We will refer to this as the efficient VaR condition. The first question can now be restated as, "Does a particular VaR measure satisfy the efficient VaR condition?"

It seems plausible that most VaRs are potentially misspecified. After all, it is hard to imagine that any econometric model underlying a VaR is an exact description of the data generating process. This would for instance be the case if the true distribution did not belong to a location-scale family. Under these circumstances, the conditional quantile of interest may not be a function of the conditional variance only, and conditional kurtosis, for example, may play an additional role in characterizing the conditional quantile. It is then likely that every VaR measure would be rejected given a sufficiently large amount of observations. We therefore want our testing methodology to allow for the possibility of misspecification. ${ }^{1}$

It is of clear interest for the risk manager to test the appropriateness of an individual VaR measure in a conditional fashion as suggested above. However, testing a number of different VaR models individually does not resolve the potential problem of ties. One could easily imagine a situation where specification tests were run on a set of models and for example half of the models passed the tests but the other half did not. This would leave open the question of choosing the best model among the ones which passed the specification tests. This section suggests a testing framework which allows pairwise comparisons of a set of models. Using a given VaR model as the benchmark, the risk manager can use the test to statically compare the benchmark models

\footnotetext{
${ }^{1}$ Of course, in finite samples, even statistical acceptance of the efficient VaR condition for some particular VaR measure does not neccesarily imply that the efficient VaR condition is satisfied in population, as a lack of power against the relevant alternative could be the culprit.
} 
to all other models in a set. Alternatively, one can of course simply test all the possible pairwise combinations.

Our second research question may be stated as, "How do we compare misspecified VaR measures?" In order to answer this question, consider now again the competing VaR measure, $F_{t \mid t-1}^{*}\left(\theta_{p}\right)$. We can write

$$
E\left[\left(I\left(y_{t}<F_{t \mid t-1}^{*}\left(\theta_{p}\right)\right)-p\right) \mid \Psi_{t-1}\right]=0
$$

We then want to test whether $F_{t \mid t-1}\left(\beta_{p}\right)$ is significantly better than $F_{t \mid t-1}^{*}\left(\theta_{p}\right)$ in a statistically meaningful way, using these moment conditions.

We have now established a moment condition framework for VaR measures but we still need to find the distribution of the moment conditions. This task is complicated by the presence of the indicator function. As it always takes on a value of either zero or one, it introduces a nondifferentiability into the moment conditions. We will resolve this complication partly by using the results of Pakes and Pollard (1989), and partly by extending the framework of Kitamura (1997).

\section{Methodology}

Recall that, if the VaR measure is correctly specified, we must have

$$
E\left[I\left(y_{t}<F_{t \mid t-1}\left(\beta_{p}\right)\right)-p \mid \Psi_{t-1}\right]=0
$$

Suppose that the instruments $\left\{z_{t-1}, z_{t-2}, \ldots\right\}$ are contained in the information set $\Psi_{t-1}$. Note that, by the law of iterated expectations, we should have

$$
E\left[\left(I\left(y_{t}<F_{t \mid t-1}\left(\beta_{p}\right)\right)-p\right) \times k\left(z_{t-1}, z_{t-2}, \ldots\right)\right]=0
$$

for every measurable vector-valued function $k(\cdot)$ of $\left\{z_{t-1}, z_{t-2}, \ldots\right\}$. For simplicity, omitting the time and $p$-subscripts, we may write equation (6) generically as $E[f(x, \beta)]=0$, where the vector $x$ contains the elements of $z_{t}$ and $y_{t}$ as well as $\sigma_{t}$.

\subsection{VaR Specification Testing}

Hansen's (1982) GMM overidentification test, sometimes known as the $J$-test, can be used to test the implication in (6). The test statistic is defined as

$$
T \bar{f}_{T}(\widehat{\beta})^{\prime} W \bar{f}_{T}(\widehat{\beta})
$$

where

$$
\widehat{\beta}=\arg \min _{\beta} \bar{f}_{T}(\beta)^{\prime} W \bar{f}_{T}(\beta), \quad \bar{f}_{T}(\beta)=\frac{1}{T} \sum_{t=1}^{T} f\left(x_{t}, \beta\right),
$$

and $W$ is the optimal weighting matrix making GMM a consistent and asymptotically efficient estimator. It is clear that, due to the presence of the indicator function, $I(\cdot)$, the moment function 
$f(x, \beta)$ is not differentiable in $\beta$, which presents an econometric challenge. For specification testing, this challenge has been resolved by Pakes and Pollard (1989) who apply simulation-based techniques. Although the standard GMM framework is thus suitable for specification testing of VaR measures, it is ill suited for nonnested comparisons of possibly misspecified models. This is the topic to which we now turn.

\subsection{Nonnested VaR Comparison}

For the specification test described at the end of the preceding subsection, we could in principle have relied on the information theoretic alternative to GMM due to Kitamura and Stutzer (1997), who consider solving the sample analog of the unconstrained problem

$$
\beta^{*}=\underset{\beta}{\operatorname{argmax}} \min _{\gamma} E_{\mu}\left[\exp \left(\gamma^{\prime} f(x, \beta)\right)\right]
$$

i.e.,

$$
\widehat{\beta}_{T}=\underset{\beta}{\operatorname{argmax}} \min _{\gamma} M_{T}(\beta, \gamma)=\underset{\beta}{\operatorname{argmax}} \min _{\gamma} \frac{1}{T} \sum_{t=1}^{T} \exp \left(\gamma^{\prime} f\left(x_{t}, \beta\right)\right) .
$$

Their estimator is based on the intuition that, under correct specification, $\beta^{*}$ minimizes the Kullback-Leibler Information criterion (KLIC), where KLIC $\equiv-\log \min _{\gamma} M(\beta, \gamma)$, and $M$ is the population counterpart of $M_{T}$ as defined in Theorem 1 below. Interestingly, their interpretation has a nice generalization to the nonnested hypothesis testing as discussed by Kitamura (1997).

Suppose now that we are given two VaR measures, $F_{t \mid t-1}\left(\beta_{p}\right)$, and $F_{t \mid t-1}^{*}\left(\theta_{p}\right)$, the moment conditions of which can be written as:

$$
E\left[f\left(x, \beta_{p}\right)\right] \equiv E\left[\left(I\left(y_{t}<F_{t \mid t-1}\left(\beta_{p}\right)\right)-p\right) \times k\left(z_{t-1}\right)\right]=0
$$

and

$$
E\left[g\left(x, \theta_{p}\right)\right] \equiv E\left[\left(I\left(y_{t}<F_{t \mid t-1}^{*}\left(\theta_{p}\right)\right)-p\right) \times k\left(z_{t-1}\right)\right]=0,
$$

where $k(\cdot)$ is a given finite-dimensional vector-valued function. Note that neither VaR measure nests the other, and traditional nested hypothesis testing cannot be used for comparing these two VaR measures. This alone presents a theoretical challenge for VaR comparisons. We take an even more ambitious position by assuming that both specifications are potentially incorrect.

Kitamura (1997) proposed to deal with such nonnested hypothesis testing by comparing the KLIC distance of the two moment restrictions in population. Under his proposal, the moment restriction with smaller KLIC distance will be accepted: Our test will be based on the difference between the KLIC distances

$$
M_{T}\left(\widehat{\beta}_{T}, \widehat{\gamma}_{T}\right)=\max _{\beta} \min _{\gamma} M_{T}(\beta, \gamma)\left(=\frac{1}{T} \sum_{t=1}^{T} \exp \left[\gamma^{\prime} f\left(x_{t}, \beta\right)\right]\right)
$$


and

$$
N_{T}\left(\widehat{\theta}_{T}, \widehat{\lambda}_{T}\right)=\max _{\theta} \min _{\lambda} N_{T}(\theta, \lambda)\left(=\frac{1}{T} \sum_{t=1}^{T} \exp \left[\lambda^{\prime} g\left(x_{t}, \theta\right)\right]\right) .
$$

Kitamura (1997) established the properties of such nonnested hypothesis testing for the case where both $f$ and $g$ are differentiable. Due to the indicator function, differentiability is violated in our application. We therefore generalize his result to our nondifferentiable case, and obtain the following result.

Theorem 1 Let

$$
\begin{aligned}
M\left(\beta^{*}, \gamma^{*}\right) & =\max _{\beta} \min _{\gamma} M(\beta, \gamma)\left(=E\left[\exp \left[\gamma^{\prime} f\left(x_{t}, \beta\right)\right]\right]\right) \\
N\left(\theta^{*}, \lambda^{*}\right) & =\max _{\theta} \min _{\lambda} N(\theta, \lambda)\left(=E\left[\exp \left[\lambda^{\prime} g\left(x_{t}, \theta\right)\right]\right]\right) .
\end{aligned}
$$

Under the null that $M\left(\beta^{*}, \gamma^{*}\right)=N\left(\theta^{*}, \lambda^{*}\right)$, we have

$$
\sqrt{T}\left(M_{T}\left(\widehat{\beta}_{T}, \widehat{\gamma}_{T}\right)-N_{T}\left(\widehat{\theta}_{T}, \widehat{\lambda}_{T}\right)\right) \rightarrow N\left(0, \sigma_{\infty}^{2}\right),
$$

where $\sigma_{\infty}^{2}=\lim _{T \rightarrow \infty} \operatorname{Var}\left(\frac{1}{\sqrt{T}} \sum_{t=1}^{T} \exp \left[\gamma^{*} \prime f\left(x_{t}, \beta^{*}\right)\right]-\exp \left[\lambda^{*} \prime g\left(x_{t}, \theta^{*}\right)\right]\right)$.

Proof. See the Appendix.

Thus, a significantly large value of the test statistic will cause a rejection of the hypothesis that the two measures match the efficient VaR condition equally well in favor of the VaR model denoted by $E\left[g\left(x, \theta^{*}\right)\right]=0$.

\section{Application to Daily Returns on the S\&P500}

The focus of this application is to assess and compare the usefulness of different volatility measures in risk management. We apply our testing methodology to a portfolio consisting of a long position in the S\&P500 index with an investment horizon of one day. The data applied was graciously provided to us by Chernov and Ghysels (2000). They provide us with S\&P500 index returns which are recorded daily from November 1985 to October 1994, corresponding to 2209 observations. They also supply a daily European options price on the at-the-money, nearest to maturity, call option contract on the S\&P500 index. Using the efficient GMM methodology of Gallant and Tauchen (1996), Chernov and Ghysels (2000) estimate the Heston's (1993) model in equation (4), and obtain a series of daily "fitted" volatilities, using the reprojection algorithm in Gallant and Tauchen (1998). We shall refer to these as reprojected volatilities below. In addition to the reprojected volatilities from Heston's model, Chernov and Ghysels produce a set of daily implied Black-Scholes volatilities defined from equation (3).

In addition to the two volatility series calculated from option prices, we apply two volatility measures based on the historical daily returns data. One is an estimated $\operatorname{GARCH}(1,1)$ volatility 
as in equation (2), the other is the so called RiskMetrics volatility which is constructed simply as an exponential filter of the squared returns, as in equation (1). As in RiskMetrics, we set the smoothing parameter, $\lambda$, to .94. The four standard deviation series are plotted in Figure 1.

For each of the volatility series, and at each desired VaR coverage, $p$, we run a simple quantile regression of returns on a constant and the time-varying standard deviation to get initial parameter estimates. We then optimize this first estimate using equation (8) to get a final parameter estimate, and thus a final $\operatorname{VaR}(p)$ measure for each model. We then turn to the testing of the four volatility measures for VaR purposes across a range of coverage values, $p$.

\subsection{VaR Specification Testing}

When testing each of the four VaRs for misspecification, we could of course use the well-known GMM $J$-test suggested in equation (7). However, in order to maintain continuity with the ensuing comparison tests, we will instead apply Kitamura and Stutzer's (1997) $\kappa$-test. The $\kappa$-test is the information theoretic version of the $J$-test, and it takes the form

$$
\hat{\kappa}_{T}=-2 T \log M_{T}\left(\widehat{\beta}_{T}, \widehat{\gamma}_{T}\right)=-2 T \log \left(\frac{1}{T} \sum_{t=1}^{T} \exp \left[\hat{\gamma}^{\prime} f\left(x_{t}, \hat{\beta}\right)\right]\right) \rightarrow \chi_{r-m}^{2}
$$

where $r$ is the number of moments, and $m$ is the number of estimated parameters. We will test the VaR measures constructed from GARCH volatilities, RiskMetrics volatilities, implied volatilities, and reprojected volatilities from the daily S\&P500 returns. We use a constant as well as the first lag of the four volatility measures as our linear conditioning information, thus $r=1+4=5$. As we are estimating two parameters: the constant and the slope on volatility, we have $m=2$, and therefore $r-m=5-2=3$ degrees of freedom in the asymptotic $\chi^{2}$ distribution. The specification testing results are summarized in the following table.

\section{Table 1: Specification Testing Across VaR Coverage Rates}

\begin{tabular}{lrrrr}
\hline VaR Measure & $p=.01$ & $p=.05$ & $p=.10$ & $p=.25$ \\
\hline \hline GARCH Volatility & 3.84 & 4.85 & 3.41 & 11.35 \\
RiskMetrics & 0.33 & 8.09 & 7.58 & 10.40 \\
Implied Volatility & 4.76 & 9.72 & 10.07 & 14.44 \\
Reprojected Volatility & 7.20 & 8.02 & 7.44 & 9.04 \\
\hline
\end{tabular}

The $\chi^{2}(3)$ distribution has a 5 percent critical value of 7.82 and a 10 percent critical value of 6.25 . Choosing the 5 percent level of significance, we see that no VaRs are rejected when the coverage rate $p=.01$, all but the GARCH VaR are rejected when $p=.05$, the implied volatility $\mathrm{VaR}$ is rejected when $p=.10$, and all VaRs are rejected when $p=.25$.

An important implication of these results is that different VaRs might be optimal for different levels of coverage. This is not surprising as all the VaR models are no doubt misspecified. The important thing to note is that our testing framework allows the user to assess the quality of a 
VaR measure given the desired coverage probability, $p$. Should a risk manager want to test a model across a set of coverage rates, he or she could simply stack the moment conditions corresponding to each $p$ in the set and run the test on all the conditions simultaneously.

\subsection{Nonnested VaR Comparison Testing}

In this section we perform the nonnested VaR comparison tests using the asymptotic result in Theorem 1. The results from performing pairwise comparison testing of the four competing VaRs are as follows:

Table 2: VaR Comparisons Across Coverage Rates

\begin{tabular}{lrrrr}
\hline VaR Model 1 vs VaR Model 2: & $p=.01$ & $p=.05$ & $p=.10$ & $p=.25$ \\
\hline \hline GARCH vs RiskMetrics & -0.88 & 0.54 & 1.32 & -0.24 \\
GARCH vs Implied & 0.21 & 0.65 & 0.93 & 0.48 \\
GARCH vs Reprojected & 0.59 & 0.40 & 0.55 & -0.34 \\
RiskMetrics vs Implied & 1.30 & 0.17 & 0.32 & 1.06 \\
RiskMetrics vs Reprojected & 1.67 & -0.01 & -0.02 & -0.28 \\
Implied vs Reprojected & 0.63 & -0.44 & -0.62 & -1.90 \\
\hline
\end{tabular}

Each entry in the table represents the test value from the null hypothesis of VaR Model 1 and VaR Model 2 being equally suitable. A value larger than 1.96 in absolute terms denotes a rejection of the null hypothesis at the 5 percent significance level, and a value larger than 1.65 denotes a rejection at the 10 percent level. A positive value indicates that VaR Model 1 is preferred, and a negative value that VaR Model 2 is preferred.

From the table, only a few rejections are possible, and only at the 10 percent significance level. At a VaR coverage of 1 percent, the RiskMetrics VaR is preferred to the reprojected volatility VaR. For $p=.25$, the reprojected volatility VaR is preferred to the implied volatility VaR.

Notice that the comparison testing results in general correspond well to the inference drawn from the specification testing exercise above. For example, two VaRs which were both rejected in the specification tests typically receive a comparison test value close to zero. Notice also that even though we do not find a lot of evidence to significantly discern between VaR measures in the comparison tests, the test values will allow for an informal pairwise ranking of nonnested VaRs, even if their differences are not statistically significant.

\section{$5 \quad$ Summary and Directions for Further Work}

Risk managers have an abundance of Value-at-Risk methodologies to choose from. Consequently, we have considered specification tests of various VaR measures. From the perspective that relevant VaR measures should satisfy an efficient VaR condition, which we define, we have provided various methodologies with which such relevance can be tested. The methodology can (i) test whether a 
VaR measure satisfies the efficient VaR condition; and (ii) compare two misspecified VaR measures. The usefulness of the new methodology was illustrated in an application to daily returns on the S\&P500 index.

Several issues are left for future research. We have implicitly assumed away estimation errors in the volatility measures which is not always justified. We have also assumed that the volatility measures are stationary. This is not without loss of generality, but we do not yet found an adequate yet theoretically rigorous way of incorporate such problems.

Finally, we note that we might be able to significantly rank more models if we change the investment horizon from one to five or ten trading days. The GARCH and RiskMetrics models typically provide very similar short-term variance forecasts, but they have very different implications for the longer term. In future work, we intend to address these issues. 


\section{A Appendix: Proof of Theorem 1}

\section{A.1 Assumptions}

1. The process $x_{t}$ is stationary.

2. $\beta \in \Theta$, a compact, $m$-dimensional set.

3. There exists a unique solution, $\left(\beta^{*}, \gamma^{*}\right)$, to the $\operatorname{problem} \max _{\beta} \min _{\gamma} E\left[\exp \left(\gamma^{\prime} f(x, \beta)\right)\right]$.

4. For sufficiently small $\delta>0, E\left[\sup _{\beta^{\prime} \in \Gamma(\beta, \delta)} \exp \left(\gamma^{\prime} f\left(x, \beta^{\prime}\right)\right)\right]<\infty$ for all vectors $\gamma$ in the neighborhood of $\gamma^{*}$. Here, $\Gamma(\beta, \delta)$ denotes an open ball of radius $\delta$ around $\beta$.

5. $E\left[f(x, \beta) f(x, \beta)^{\prime}\right]$ is nonsingular for all $\beta$ in $\Theta$.

6. $f(x, \beta)$ belongs to a measurable V-C subgraph class of functions the p-th moment of which envelope function is finite.

7. The process $x_{t}$ is $\beta$ mixing with $\beta$ mixing coefficients $\beta_{k}$ satisfying $k^{p /(p-2)}(\log k)^{2(p-1) /(p-2)} \beta_{k} \rightarrow$ 0 for some $2<p<\infty$.

8. $D \equiv \frac{\partial^{2}}{\partial \gamma \partial \beta^{\prime}} E\left[\exp \left(\gamma^{*^{\prime}} f\left(x, \beta^{*}\right)\right)\right]$ is of full column rank.

$V \equiv \lim _{T \rightarrow \infty} \operatorname{Var}\left[\frac{1}{T} \sum_{t=1}^{T} \exp \left(\gamma^{*^{\prime}} f\left(x_{t}, \beta^{*}\right)\right) f\left(x_{t}, \beta^{*}\right)\right]$ is positive definite.

9. $x_{t}$ is a continuous random variable, and there is an integrable $\Re^{r}$-valued function $F(x)$ such that

$$
\begin{aligned}
\left|\exp \left(\gamma^{\prime} f(x, \beta)\right) f(x, \beta)\right| & \leq F(x), \\
\left|\exp \left(\gamma^{\prime} f(x, \beta)\right) f(x, \beta)^{2}\right| & \leq F(x), \\
\left|\exp \left(\gamma^{\prime} f(x, \beta)\right) f(x, \beta)^{3}\right| & \leq F(x),
\end{aligned}
$$

for all $x$ in a neighborhood of $\left(\beta^{*}, \gamma^{*}\right)$, where $|\cdot|$, power, and $\leq$ are element-by-element.

We also impose conditions on $\theta, \lambda$, and $g(x, \theta)$ which correspond to Assumptions 2-8.

\section{A.2 Theorem}

Under Assumptions 1-8,

(a) $\left(\widehat{\beta}_{T}, \widehat{\gamma}_{T}\right) \stackrel{p}{\rightarrow}\left(\beta^{*}, \gamma^{*}\right)$.

(b) $\sqrt{T}\left(\widehat{\beta}_{T}-\beta^{*}\right)=O_{p}(1)$, and $\sqrt{T}\left(\widehat{\gamma}_{T}-\gamma^{*}\right)=O_{p}(1)$.

(c) Under the null hypothesis that $M\left(\beta^{*}, \gamma^{*}\right)=N\left(\theta^{*}, \lambda^{*}\right)$,

$$
\sqrt{T}\left(M_{T}\left(\widehat{\beta}_{T}, \widehat{\gamma}_{T}\right)-N_{T}\left(\widehat{\theta}_{T}, \widehat{\lambda}_{T}\right)\right) \stackrel{d}{\rightarrow} N\left(0, \sigma_{\infty}^{2}\right),
$$

where $\sigma_{\infty}^{2}=\lim _{T \rightarrow \infty} \operatorname{Var}\left(\frac{1}{\sqrt{T}} \sum_{t=1}^{T}\left(\exp \left[\left(\gamma^{*}\right)^{\prime} f\left(x_{t}, \beta^{*}\right)\right]-\exp \left[\left(\lambda^{*}\right)^{\prime} g\left(x_{t}, \theta^{*}\right)\right]\right)\right)$. 


\section{A.3 Sketch of Proof}

In this section we will sketch the main steps of the proof. The complete proof is available upon request.

\section{A.3.1 (a): consistency}

The proof of (a) takes the following steps. First, it follows from Kitamura and Stutzer's (1997) consistency proof, which does not require differentiability, that

1. Let $\gamma(\beta) \equiv \operatorname{argmin}_{\gamma} M(\beta, \gamma)$, then $\gamma(\beta)$ is continuous in $\beta$ under Assumption 5 .

2. Let $L \equiv E\left\{\exp \left[\gamma\left(\beta^{*}\right)^{\prime} f\left(x, \beta^{*}\right)\right]\right\}$. We have

$$
E\left\{\exp \left[\gamma(\beta)^{\prime} f(x, \beta)\right]\right\}<L
$$

and

$$
\lim _{\delta \rightarrow 0} E\left[\sup _{\beta^{\prime} \in \Gamma(\beta, \delta)} \exp \left(\gamma\left(\beta^{\prime}\right)^{\prime} f\left(x, \beta^{\prime}\right)\right)\right]=E\left\{\exp \left[\gamma(\beta)^{\prime} f(x, \beta)\right]\right\}
$$

3. For all $\delta>0$, there exists some $h>0$ such that

$$
\lim _{T \rightarrow \infty} \operatorname{Pr}\left[\sup _{\beta^{\prime} \in \Theta-\Gamma\left(\beta^{*}, \delta\right)} \frac{1}{T} \sum_{t=1}^{T} \exp \left(\gamma\left(\beta^{\prime}\right)^{\prime} f\left(x_{t}, \beta^{\prime}\right)\right)>L-h\right]=0 .
$$

4. By definition,

$$
\frac{1}{T} \sum_{t=1}^{T} \exp \left(\widehat{\gamma}_{T}(\beta)^{\prime} f\left(x_{t}, \beta\right)\right) \leq \frac{1}{T} \sum_{t=1}^{T} \exp \left(\gamma(\beta)^{\prime} f\left(x_{t}, \beta\right)\right),
$$

which, when combined with (9), yields

$$
\lim _{T \rightarrow \infty} \operatorname{Pr}\left[\sup _{\beta^{\prime} \in \Theta-\Gamma\left(\beta^{*}, \delta\right)} \frac{1}{T} \sum_{t=1}^{T} \exp \left(\widehat{\gamma}_{T}\left(\beta^{\prime}\right)^{\prime} f\left(x_{t}, \beta^{\prime}\right)\right)>L-h\right]=0 .
$$

Second, by using Pollard's (1991) arguments, one can show that $\hat{\gamma}_{T}\left(\beta^{*}\right)=\gamma\left(\beta^{*}\right)+o_{p}(1)$, and

$$
\lim _{n \rightarrow \infty} \operatorname{Pr}\left[\frac{1}{T} \sum_{t=1}^{T} \exp \left(\widehat{\gamma}_{T}\left(\beta^{*}\right)^{\prime} f\left(x_{t}, \beta^{*}\right)\right)<L-h\right]=0,
$$

where $\widehat{\gamma}_{T}\left(\beta^{*}\right)=\frac{1}{T} \sum_{t=1}^{T} \exp \left(\gamma^{\prime} f\left(x_{t}, \beta^{*}\right)\right)$.

Third, combining (10) and (11) delivers the consistency of $\widehat{\beta}_{T}$. Lastly, it follows from Theorem 2.1 of Arcones and Yu (1994) and Theorem 10.2 of Pollard (1990) that

$$
\frac{1}{T} \sum_{t=1}^{T} \exp \left(\gamma^{\prime} f\left(x_{t}, \widehat{\beta}\right)\right) \stackrel{p}{\rightarrow} E\left[\exp \left(\gamma^{\prime} f\left(x, \beta^{*}\right)\right)\right]
$$

An application of Pollard's (1991) convexity lemma completes the proof of the consistency of $\hat{\gamma}_{T}$. 


\section{A.3.2 (b): $\sqrt{T}$-consistency}

First, by using quadratic approximations, the definition of minimization and the convexity lemma, one can show that

$$
\frac{1}{T} \sum_{t=1}^{T} f\left(x_{t}, \widehat{\beta}_{T}\right) \exp \left[\gamma^{* \prime} f\left(x_{t}, \widehat{\beta}_{T}\right)\right]=O_{p}\left(\frac{1}{\sqrt{T}}\right)
$$

Next, we obtain

$$
\begin{aligned}
\frac{1}{T} \sum_{t=1}^{T} \exp \left[\gamma^{* \prime} f\left(x_{t}, \widehat{\beta}_{T}\right)\right] f\left(x_{t}, \widehat{\beta}_{T}\right) & \\
& =\frac{1}{T} \sum_{t=1}^{T} \exp \left[\gamma^{* \prime} f\left(x_{t}, \beta^{*}\right)\right] f\left(x_{t}, \beta^{*}\right)+D\left(\widehat{\beta}_{T}-\beta^{*}\right)+o_{p}\left(\frac{1}{\sqrt{T}}\right)
\end{aligned}
$$

by the usual stochastic equicontinuity argument, where the stochastic equicontinuity follows from Theorem 2.1 of Arcones and Yu and Theorem 10.2 of Pollard (1990). Because

$$
\frac{1}{\sqrt{T}} \sum_{t=1}^{T} f\left(x_{t}, \widehat{\beta}_{T}\right) \exp \left[\gamma^{* \prime} f\left(x_{t}, \widehat{\beta}_{T}\right)\right]=O_{p}(1), \quad \frac{1}{\sqrt{T}} \sum_{t=1}^{T} \exp \left[\gamma^{* \prime} f\left(x_{t}, \beta^{*}\right)\right] f\left(x, \beta^{*}\right)=O_{p}(1),
$$

we obtain

$$
\sqrt{T}\left(\widehat{\beta}_{T}-\beta^{*}\right)=O_{p}(1)
$$

By applying Pollard's (1991) argument to quadratic approximations, one can also show that

$$
\begin{aligned}
\sqrt{T}\left(\widehat{\gamma}_{T}\left(\widehat{\beta}_{T}\right)-\gamma^{*}\right) & \\
& =S^{-1} \times\left[\frac{1}{\sqrt{T}} \sum_{t=1}^{T} \exp \left[\gamma^{* \prime} f\left(x_{t}, \beta^{*}\right)\right] f\left(x_{t}, \beta^{*}\right)+D \sqrt{T}\left(\widehat{\beta}_{T}-\beta^{*}\right)\right]+o_{p}(1),
\end{aligned}
$$

Because $\frac{1}{\sqrt{T}} \sum_{t=1}^{T} \exp \left[\gamma^{* \prime} f\left(x_{t}, \beta^{*}\right)\right] f\left(x, \beta^{*}\right)=O_{p}(1)$ and $\sqrt{T}\left(\widehat{\beta}_{T}-\beta^{*}\right)=O_{p}(1)$, we obtain

$$
\sqrt{T}\left(\widehat{\gamma}_{T}-\gamma^{*}\right)=O_{p}(1)
$$

\section{A.3.3 (c): nonnested hypothesis testing}

Suppose we want to compare

$$
\sqrt{T}\left(M_{T}\left(\widehat{\beta}_{T}, \widehat{\gamma}_{T}\right)-N_{T}\left(\widehat{\theta}_{T}, \widehat{\lambda}_{T}\right)\right) .
$$

Note that

$$
\sqrt{T}\left(M_{T}\left(\widehat{\beta}_{T}, \widehat{\gamma}_{T}\right)-M\left(\beta^{*}, \gamma^{*}\right)\right)=\sqrt{T}\left(M\left(\widehat{\beta}_{T}, \widehat{\gamma}_{T}\right)-M_{T}\left(\beta^{*}, \gamma^{*}\right)\right)+o_{p}(1)
$$


by the usual stochastic equicontinuity argument. Since

$$
\sqrt{T}\left(M\left(\widehat{\beta}_{T}, \widehat{\gamma}_{T}\right)-M\left(\beta^{*}, \gamma^{*}\right)\right)=\frac{\partial M}{\partial \beta^{\prime}} \cdot \sqrt{T}\left(\widehat{\beta}_{T}-\beta^{*}\right)+\frac{\partial M}{\partial \gamma^{\prime}} \cdot \sqrt{T}\left(\widehat{\gamma}_{T}-\gamma^{*}\right)+o_{p}(1)=o_{p}(1),
$$

and

$$
\frac{\partial M}{\partial \beta^{\prime}}=0, \quad \frac{\partial M}{\partial \gamma^{\prime}}=0
$$

by the first order condition in population, it follows that

$$
\sqrt{T}\left(M_{T}\left(\widehat{\beta}_{T}, \widehat{\gamma}_{T}\right)-M\left(\beta^{*}, \gamma^{*}\right)\right)=\sqrt{T}\left(M_{T}\left(\beta^{*}, \gamma^{*}\right)-M\left(\beta^{*}, \gamma^{*}\right)\right)+o_{p}(1) .
$$

Similarly, we obtain

$$
\sqrt{T}\left(N_{T}\left(\widehat{\theta}_{T}, \widehat{\lambda}_{T}\right)-N\left(\theta^{*}, \lambda^{*}\right)\right)=\sqrt{T}\left(N_{T}\left(\theta^{*}, \lambda^{*}\right)-N\left(\theta^{*}, \lambda^{*}\right)\right)+o_{p}(1) .
$$

Therefore, under the null that

$$
M\left(\beta^{*}, \gamma^{*}\right)=N\left(\theta^{*}, \lambda^{*}\right),
$$

we have

$$
\begin{aligned}
\sqrt{T}\left(M_{T}\left(\widehat{\beta}_{T}, \widehat{\gamma}_{T}\right)-N_{T}\left(\widehat{\theta}_{T}, \widehat{\lambda}_{T}\right)\right) & =\sqrt{T}\left(M_{T}\left(\beta^{*}, \gamma^{*}\right)-N_{T}\left(\theta^{*}, \lambda^{*}\right)\right)+o_{p}(1) \\
& \stackrel{d}{\rightarrow} N\left(0, \sigma_{\infty}^{2}\right)
\end{aligned}
$$




\section{References}

[1] Andersen, T. and T. Bollerslev (1998), "Answering the Critics: Yes, ARCH Models do Provide Good Volatility Forecasts," International Economic Review, 39, 885-905.

[2] Andersen, T., T. Bollerslev, F. Diebold and P. Labys (1999), "The Distribution of Exchange Rate Volatility," forthcoming in the Journal of the American Statistical Association.

[3] Arcones, M.A. and B. Yu (1994) "Central Limit Theorems for Empirical and U-Processes of Stationary Mixing Sequences," Journal of Theoretical Probability, 7, 47-71.

[4] Beder, T. (1995), "VaR: Seductive but Dangerous," Financial Analysts Journal, SeptemberOctober, 12-24.

[5] Black, F. and M. Scholes (1972), "The Valuation of Options and Corporate Liabilities," Journal of Political Economy, 81, 637-654.

[6] Bollerslev, T. (1986), "Generalized Autoregressive Conditional Heteroskedasticity," Journal of Econometrics, 31, 307-327.

[7] Chernov, M. and E. Ghysels (2000), "A Study towards a Unified Approach to the Joint Estimation of Objective and Risk Neutral Measures for the Purpose of Options Valuation" Journal of Financial Economics, 56, 407-458.

[8] Christoffersen, P. (1998), "Evaluating Interval Forecasts," International Economic Review, 39, 841-862.

[9] Danielsson, J. and C. de Vries (1997), "Value at Risk and Extreme Returns," Manuscript, London School of Economics.

[10] Dimson, E. and P. Marsh (1995), "Capital Requirements for Securities Firms," Journal of Finance, 50, 821-851.

[11] Dowd, K. (1998), Beyond Value at Risk: The New Science of Risk Management. Wiley.

[12] Duffie, D. and J. Pan (1997), "An Overview of Value at Risk," Journal of Derivatives, 4, 7-49.

[13] Engle. R. (1982), "Autoregressive Conditional Heteroskedasticity with Estimates of the Variance of United Kingdom Inflation," Econometrica, 50, 987-1007.

[14] Engle, R. and S. Manganelli (1999), "CAViaR: Conditional Autoregressive Value at Risk by Regression Quantiles," Manuscript, UCSD.

[15] Gallant, R. and G. Tauchen (1996), "Which Moments to Match?," Econometric Theory, 12, 657-681.

[16] Gallant, R. and G. Tauchen (1998), "Reprojecting Partially Observed Systems with Application to Interest Rate Diffusions, Journal of the American Statistical Association, 93, 10-24. 
[17] Garman, M. and M. Klass (1980), "On the Estimation of Security Price Volatilities from Historical Data," Journal of Business, 53, 67-78.

[18] Hansen, L. (1982), " Large Sample Properties of Generalized Method of Moments Estimators," Econometrica, 50, 1029-1054.

[19] Hendricks, D. (1996), "Evaluation of Value-at-Risk Models Using Historical Data," Federal Reserve Bank of New York Economic Policy Review, April, 39-70.

[20] Heston, S. (1993), "A Closed-Form Solution for Options with Stochastic Volatility with Applications to Bond and Currency Options, Review of Financial Studies, 6, 327-343.

[21] Jorion, P. (1995), "Predicting Volatility in the Foreign Exchange Market," Journal of Finance, $50,507-528$.

[22] Jorion, P. (1996), Value at Risk: The New Benchmark for Controlling Market Risk. Irwin Professional.

[23] JP Morgan (1996), RiskMetrics, Technical Document. 4th Edition. New York.

[24] Kitamura, Y. (1997), "Comparing Misspecified Dynamic Econometric Models Using Nonparametric Likelihood," Manuscript, Department of Economics, University of Wisconsin, Madison.

[25] Kitamura, Y. and M. Stutzer (1997), "Information Theoretic Alternative to Generalized Method of Moments Estimation," Econometrica, 65, 861-874.

[26] Marshall, C. and M. Siegel (1997), "Value at Risk: Implementing a Risk Measurement Standard," Journal of Derivatives, 4, 91-111.

[27] Pakes, A., and D. Pollard (1989), "Simulation and the Asymptotics of Optimization Estimators," Econometrica, 57, $1027-57$.

[28] Pollard, D. (1990), Empirical Processes: Theory and Applications, Institute of Mathematical Statistics, Hayward, CA.

[29] Pollard, D. (1991), "Asymptotics for Least Absolute Deviation Regression Estimators," Econometric Theory, 7, 186-199.

[30] Risk (1999), "Risk Software Survey 1998" Risk, January, 67-80.

[31] Wagster, J. (1996), "Impact of the 1988 Basle Accord on International Banks," Journal of Finance, 51, 1321-1346. 
Figure 1: Four Volatility Measures of Daily S\&P500 Returns
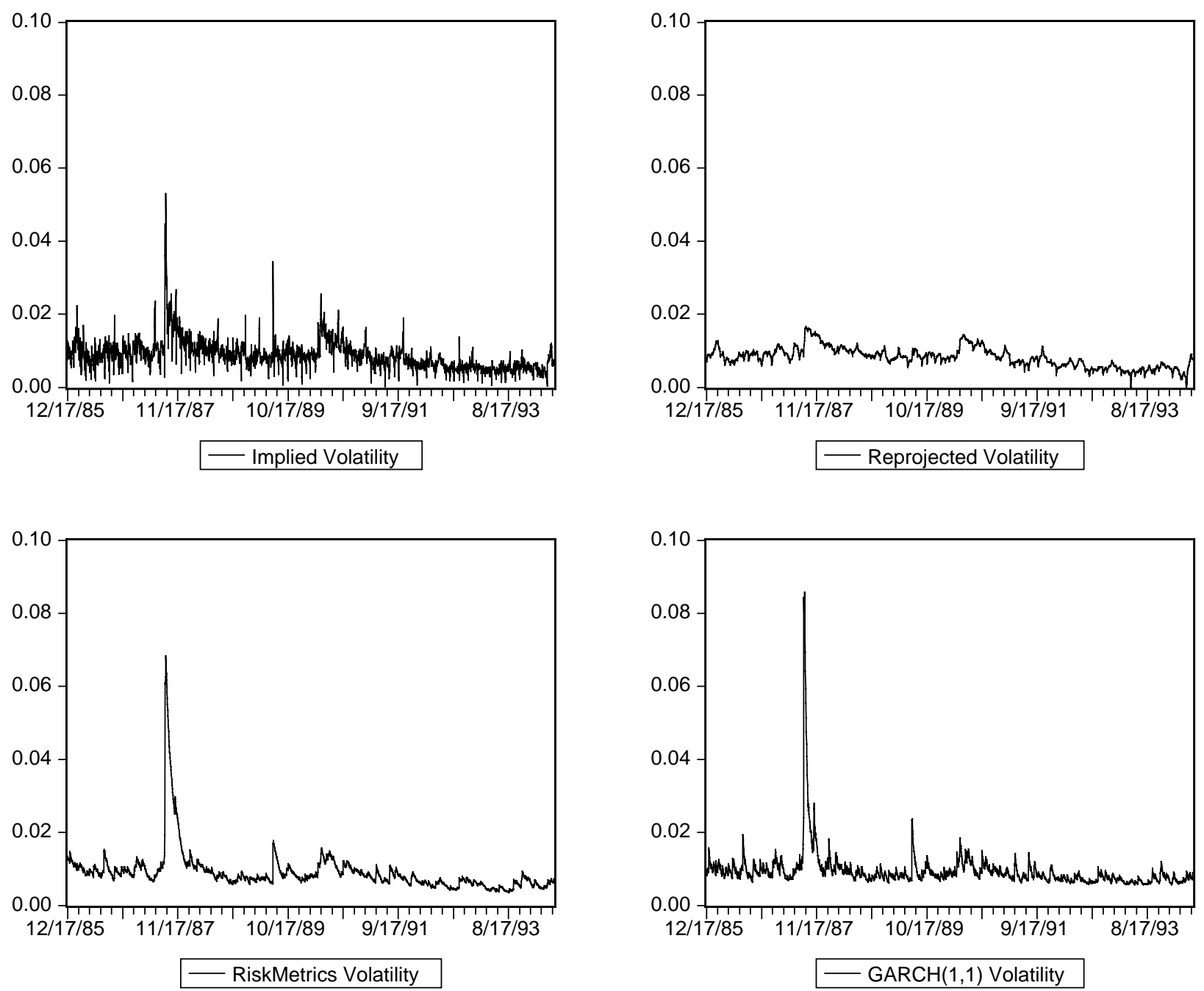


\section{Liste des publications au CIRANO *}

\section{Cahiers CIRANO / CIRANO Papers (ISSN 1198-8169)}

99c-1 Les Expos, l'OSM, les universités, les hôpitaux : Le coût d'un déficit de 400000 emplois au Québec — Expos, Montréal Symphony Orchestra, Universities, Hospitals: The Cost of a 400,000-Job Shortfall in Québec / Marcel Boyer

96c-1 Peut-on créer des emplois en réglementant le temps de travail? / Robert Lacroix

95c-2 Anomalies de marché et sélection des titres au Canada / Richard Guay, Jean-François L'Her et Jean-Marc Suret

95c-1 La réglementation incitative / Marcel Boyer

94c-3 L'importance relative des gouvernements: causes, conséquences et organisations alternative / Claude Montmarquette

94c-2 Commercial Bankruptcy and Financial Reorganization in Canada / Jocelyn Martel

94c-1 Faire ou faire faire : La perspective de l'économie des organisations / Michel Patry

Série Scientifique / Scientific Series (ISSN 1198-8177)

2001s-02 Empirical Assessment of an Intertemporal Option Pricing Model with Latent Variables / René Garcia, Richard Luger et Éric Renault

2001s-01 Asymmetric Smiles, Leverage Effects and Structural Parameters / René Garcia, Richard Luger et Éric Renault

2000s-60 Technological Paradigms and the Measurement of Innovation / Bernard SinclairDesgagné

2000s-59 Taxpayers' Response to Tax Rate Changes: A Canadian Panel Study / Robert Gagné, Jean-François Nadeau et François Vaillancourt

2000s-58 Competition and the Reform of Incentive Schemes in the Regulated Sector / Marcel Boyer et Jean-Jacques Laffont

2000s-57 Law versus Regulation: A Political Economy Model of Instrument Choice in Environmental Policy / Marcel Boyer et Donatella Porrini

2000s-56 Le retour à l'école / Marcel Dagenais, Claude Montmarquette, Nathalie Viennot-Briot et Muriel Meunier

2000s-55 Le décrochage scolaire, la performance scolaire et le travail pendant les études : un modèle avec groupe hétérogène / Marcel Dagenais, Claude Montmarquette, Nathalie Viennot-Briot et Muriel Meunier

2000s-54 Vertical R\&D Spillovers, Cooperation, Market Structure, and Innovation / Gamal Atallah

2000s-53 Information Sharing and the Stability of Cooperation in Research Joint Ventures / Gamal Atallah

\footnotetext{
* Vous pouvez consulter la liste complète des publications du CIRANO et les publications elles-mêmes sur notre site
} Internet à l'adresse suivante :

http://www.cirano.umontreal.ca/publication/documents.html 